\title{
openheart Surgical treatment for infective endocarditis in the ageing society: a nationwide retrospective study in Japan
}

\section{Hiroyuki Kiriyama (D) , ${ }^{1}$ Hidehiro Kaneko (D) , ${ }^{1,2}$ Hidetaka Itoh, ${ }^{1}$ Tatsuya Kamon, ${ }^{1}$ Kojiro Morita, ${ }^{3,4}$ Taisuke Jo, ${ }^{5}$ Katsuhito Fujiu, ${ }^{1,2}$ Masao Daimon, ${ }^{1}$ Norifumi Takeda, ${ }^{1}$} Hiroyuki Morita, ${ }^{1}$ Hideo Yasunaga, ${ }^{3}$ Issei Komuro ${ }^{1}$

\begin{abstract}
- Additional supplemental material is published online only. To view, please visit the journal online (http://dx.doi.org/10. 1136/openhrt-2021-001627).

To cite: Kiriyama $\mathrm{H}$, Kaneko $\mathrm{H}$, Itoh $\mathrm{H}$, et al. Surgical treatment for infective endocarditis in the ageing society: a nationwide retrospective study in Japan. Open Heart 2021;8:e001627. doi:10.1136/
\end{abstract}

openhrt-2021-001627

Received 12 March 2021 Revised 25 March 2021 Accepted 25 March 2021

Check for updates

(c) Author(s) (or their employer(s)) 2021. Re-use permitted under CC BY-NC. No commercial re-use. See rights and permissions. Published by BMJ.

${ }^{1}$ Department of Cardiovascular Medicine, The University of Tokyo, Bunkyo-ku, Japan ${ }^{2}$ Department of Advanced Cardiology, The University of Tokyo, Bunkyo-ku, Japan ${ }^{3}$ Department of Clinical Epidemiology and Health Economics, School of Public Health, The University of Tokyo, Bunkyo-ku, Japan

${ }^{4}$ Department of Health Services Research, Faculty of Medicine, University of Tsukuba, Tsukuba, Japan

${ }^{5}$ Department of Health Services Research, The University of Tokyo, Bunkyo-ku, Japan

Correspondence to Dr Hiroyuki Kiriyama; kiriyaman0427@gmail.com

\section{ABSTRACT}

Objective The current status of surgical treatment for infective endocarditis (IE) among very elderly people is unclear.

Methods We extracted data on patients in Japan with community-acquired IE who were admitted and discharged between April 2010 and February 2018 using a nationwide inpatient, the Diagnosis Procedure Combination database. We divided patients into three groups: non-elderly ( $<65$ years), elderly $(65-79$ years) and very elderly ( $\geq 80$ years). A 1:1 propensity score matching was performed to compare proportions of surgical treatment and in-hospital mortality among the groups. Results We identified 20667 eligible patients (median age 70 years, $61.0 \%$ men). The proportion of very elderly patients significantly increased $(19.1 \%$ in 2010 to $29.7 \%$ in 2018). The proportion of surgical treatment was significantly lower, and in-hospital mortality was significantly higher in very elderly patients. This tendency was more pronounced among patients with in-hospital complications such as heart failure, stroke or embolism. Surgical treatment was significantly associated with lower in-hospital mortality even in very elderly patients, both in an unmatched (OR 0.61; $95 \% \mathrm{Cl} 0.47$ to 0.78 ) and a propensity score matched cohort (OR 0.61; $95 \% \mathrm{Cl} 0.43$ to 0.85 ).

Conclusions The proportion of very elderly patients with IE was increasing, and very elderly patients had higher in-hospital mortality. The proportion of surgical treatment for IE among very elderly patients was low, but it was associated with lower in-hospital mortality. Further studies are needed to establish the optimal strategy for IE among very elderly patients.

\section{INTRODUCTION}

Infective endocarditis (IE) is a rare infectious disease that nevertheless has a high burden of mortality and morbidity. The annual incidence of IE is 3-10 cases per 100000 inhabitants in developed countries ${ }^{1-5}$; however, short-term IE mortality is up to $25 \%$ and has not changed in the last decade despite recent improvements in diagnosis and management. $^{267}$

\section{Key questions}

What is already known about this subject?

- The incidence of infective endocarditis (IE) among elderly patients over 80 years old has doubled in the last few decades, which can be an unignorable issue. However, previous studies have defined elderly individuals as those older than 65 or 70 years because the scarcity of IE makes sampling difficult. Therefore, previous results do not reflect the current status of IE in the ageing population.

What does this study add?

- Our study elucidates the current status of surgical treatment and in-hospital mortality for IE in very elderly patients aged 80 years or older using a nationwide inpatient database in Japan.

How might this impact on clinical practice?

- IE among very elderly patients was rapidly increasing, and very elderly patients had higher in-hospital mortality than non-elderly patients. Although surgical treatment was less frequently conducted in very elderly patients, it was associated with lower in-hospital mortality even after propensity score matching. Our findings highlight the clinical importance of selecting optimal candidates for surgical treatment even in very elderly patients with IE.

One possible reason for the sustained high mortality of IE is the current ageing population. Although ageing is a well-known strong prognostic factor for IE, ${ }^{68}$ some epidemiological studies showed that the incidence of IE among very elderly patients aged 80 years or older doubled in the last few decades while the overall incidence has remained static. ${ }^{59}$

Ageing is a heterogeneous process which results in a wide spectrum of patients' profile, and optimal IE management of very elderly patients should be differentiated from that of non-elderly patients. Particularly, the current status of surgical treatment, which is a cornerstone of IE treatment, is still unclear among very elderly patients. Previous studies 
suggest that surgical treatment has a beneficial effect on IE among elderly patients. ${ }^{10-17}$ In those studies, elderly patients were defined as those over 65 or 70 years, owing to the rarity of IE and the difficulty of collecting sufficient target samples. ${ }^{10-17}$

In the real-world clinical setting, the number of healthier elderly people is increasing. Such individuals may be suited to similar treatment strategies as non-elderly people; in contrast, clinicians struggle to manage very elderly patients with IE. However, observational studies of very elderly people are scarce, and rarely mentioned in the guidelines of the American Heart Association and the European Society of Cardiology. ${ }^{18} 19$

Japan is the most rapidly ageing society in the world and is confronting various unique geriatric issues. The current status of very elderly patients with IE in Japan may be an indicator of the future worldwide status of IE. In the present study, we used a nationwide Japanese inpatient database to elucidate the current status of surgical treatment and clinical outcomes among very elderly patients hospitalised with IE.

\section{METHODS}

\section{Study design and data source}

This was a retrospective cohort study using the Diagnosis Procedure Combination database, a nationwide Japanese inpatient database. ${ }^{20} 21$ This database contains hospital administrative claims data and clinical data for approximately 8 million hospitalised patients per year from participating hospitals, including more than 1000 acute care hospitals and all 82 academic hospitals. The database includes the following data: individual hospital identifier; patient admission and discharge date; patient background (eg, age and sex); consciousness level at admission according to Japan Coma Scale (JCS) score ${ }^{22}$; diagnosis at admission including main diagnosis, admissionprecipitating diagnosis, and most and second most resource-consuming diagnosis; comorbidities at admission and complications after admission as described by the International Classification of Diseases and Related Health Problems, 10th Revision (ICD-10) codes; daily records of drugs, devices and procedures, including surgical treatment, coded with original code during hospitalisation; and discharge status.

\section{Patient and public involvement}

Patients or the public were not involved in this research project.

\section{Patient selection}

We identified patients with IE aged $\geq 20$ years who were admitted and discharged between 1 April 2010 and 28 February 2018. Records of patients with IE were extracted using the relevant ICD-10 code with the main diagnosis, admission-precipitating diagnosis, or most and second most resource-consuming diagnosis (see online supplemental table 1 ). Only the first episode of IE recorded for an individual during study enrolment, for which any antibiotics were started within 2 days after admission, was counted as community-acquired IE and used for the analysis. Eligible patients were divided into three groups: nonelderly ( $<65$ years), elderly (65-79 years) and very elderly ( $\geq 80$ years).

\section{Variables and outcomes}

For baseline variables, we obtained data on patient characteristics: patient age and sex; body mass index (BMI) categorised as <18.5, 18.5-24.9, 25.0-29.9, $\geq 30 \mathrm{~kg} / \mathrm{m}^{2}$; smoking and activities of daily living (Barthel Index score categorised as $<20$ (total dependence), 20-35 (severe dependence), 40-55 (moderate dependence), 60-95 (mild dependence) and 100 (independence) ${ }^{23}$; consciousness level at admission according to JCS score ${ }^{22}$; type of admission (planned or emergency); and supply of pre-hospital home medical care. We extracted data on hypertension, diabetes mellitus, dyslipidaemia, atrial fibrillation, malignancy, chronic pulmonary disease, chronic liver disease, chronic renal disease and previous valve replacement as comorbid conditions at admission (see online supplemental table 1). The data on hospital volume were classified into three groups (low, middle, high) and type of hospital was recorded (eg, clinical training hospital). For in-hospital complications, we extracted data on heart failure (with New York Heart Association classification if listed); stroke, including ischaemia and haemorrhage; any embolism of the coronary system, spleen, kidney, lung, abdominal artery or extremities; shock; and disseminated intravascular coagulation as common complications of IE (see online supplemental table 1). We defined penicillin system, cephem system, carbapenem, aminoglycoside, glycopeptide, daptomycin, linezolid and antifungal antibiotics used for more than 2 weeks during hospitalisation as antibiotics targeted to IE. Transthoracic echocardiography and transoesophageal echocardiography (TEE) during hospitalisation were investigated. Data on intensive treatment within 2 days after admission, including admission to high care unit/intensive care unit, inotropic therapy and mechanical support (ventilation support, renal replacement therapy and direct hemoperfusion with polymyxin B immobilised fibre), were extracted for severity assessment. Surgical treatment for IE was defined according to the following ICD-10 codes: K542, K554, K555, K557-3 and K560.

\section{Statistical analysis}

Categorical variables are shown as numbers (percentages) and consecutive data are presented as medians (IQRs). $\chi^{2}$ tests were used to compare categorical variables and the Kruskal-Wallis test was used to compare consecutive variables. A 1:1 propensity score matching was conducted using nearest neighbour matching with a calliper width set at $20 \%$ SD 
of the logit of the estimated propensity scores to adjust differences in baseline characteristics between patients with and without surgical treatment among the three subgroups (non-elderly, elderly and very elderly). The propensity score was estimated using a non-parsimonious logistic regression model with surgical treatment as the dependent variable. Covariates included in this model were baseline characteristics, admission year, hospital type, admission type, comorbid conditions, complications, antibiotics and procedures within 2 days (see online supplemental table 2a-c). Differences between the two groups before and after propensity score matching were assessed using standardised mean differences. Absolute standardised mean differences of less than $10 \%$ suggest a negligible difference in baseline characteristics between two groups. ${ }^{24}$ The multivariate logistic regression analysis was performed to find factors associated with in-hospital mortality among very elderly patients with IE. In this model, in-hospital mortality was adopted as a dependent variable, and independent variables included baseline characteristics, hospital type, comorbid conditions and complications. We performed statistical analyses using IBM SPSS (V.25.0; IBM SPSS) and Stata (V.16; Stata Corp). $P$ values of $<0.05$ were considered statistically significant.

\section{RESULTS}

\section{Study population}

We studied 20667 eligible patients with communityacquired IE. The distribution of non-elderly, elderly and very elderly patients was $7803(37.8 \%), 7874$ $(38.1 \%)$ and $4990(24.1 \%)$, respectively.

Figure 1 shows the transition of IE prevalence according to age category. The proportion of non-elderly patients decreased from $42.5 \%$ in 2010 to $32.1 \%$ in 2018 , and that of elderly patients remained unchanged from $38.5 \%$ in 2010 to $38.2 \%$ in 2018 . The proportion of very elderly patients significantly increased from $19.1 \%$ in 2010 to $29.7 \%$ in 2018.

\section{Baseline patient characteristics}

Table 1 summarises the baseline characteristics for all patients. The median age was 70 years (57-79 years), and 12603 patients $(61.0 \%)$ were men. The median BMI was 21.3 (19.0-23.9). Very elderly patients were more likely to be women and have lower BMI and lower Barthel Index scores than non-elderly patients. Furthermore, very elderly patients had more emergency hospitalisations and lower consciousness at admission than non-elderly patients. Most comorbid conditions, including hypertension, diabetes mellitus, dyslipidaemia, atrial fibrillation and malignancy, significantly increased with age. Regarding IE complications, heart failure occurred more frequently in very elderly patients, whereas stroke and all types of embolism were more common in non-elderly patients.

\section{Antibiotic therapy, echocardiography and procedures}

Table 2 shows antibiotic use, echocardiography use and intensive treatment during hospitalisation. Penicillin system, cephem system and aminoglycoside were administered more frequently to non-elderly patients. Glycopeptide, daptomycin and antifungal antibiotics were administered more frequently to elderly patients. Regarding echocardiography, more than $90 \%$ of patients in each age category received transthoracic echocardiography, whereas the proportion of TEE was significantly lower in very elderly patients. Regarding intensive treatment within 2 days after admission, non-elderly patients more frequently received intensive treatment such as admission to

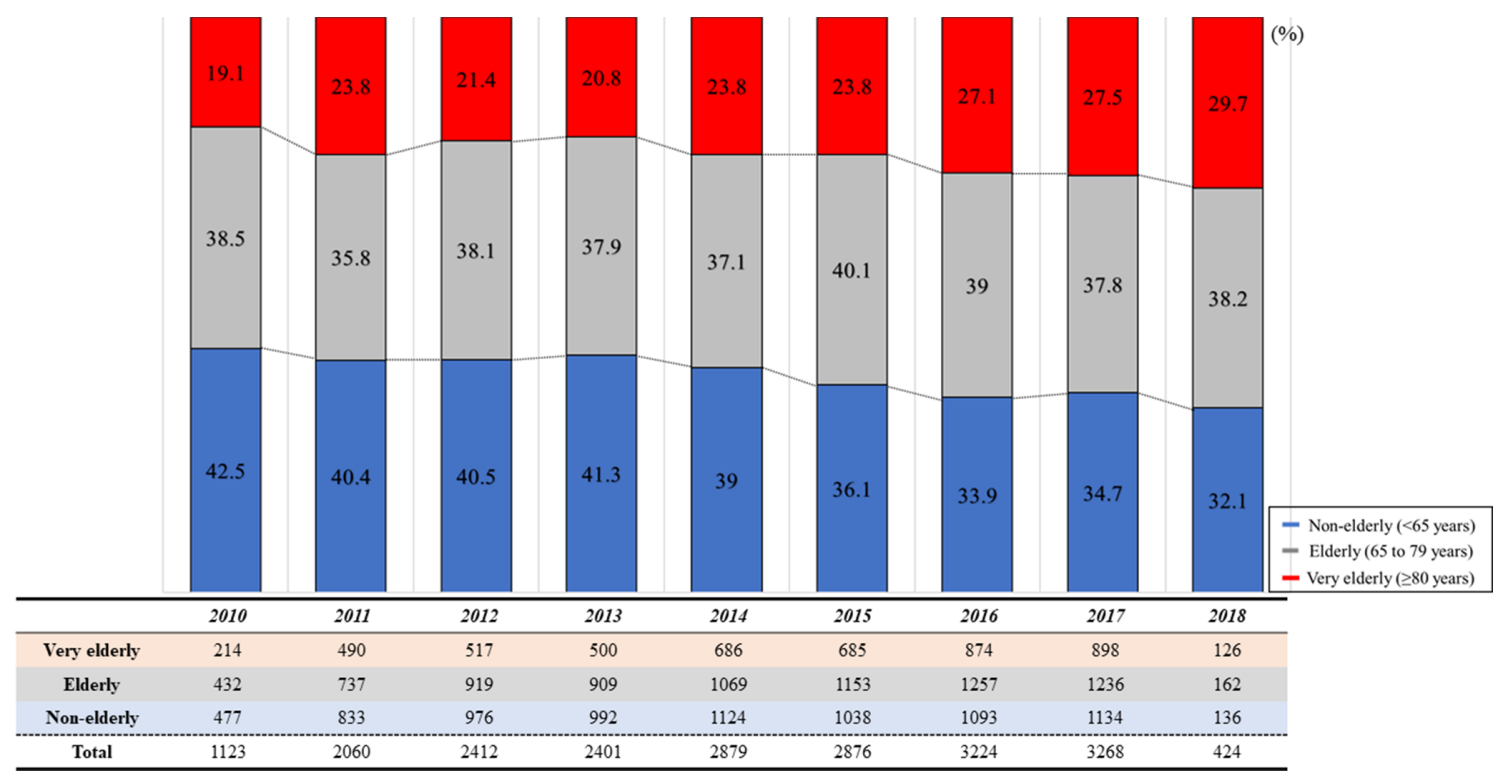

Figure 1 Transition of IE prevalence according to age category. The proportion of the non-elderly patients decreased, and that of the very elderly patients significantly increased, from April 2010 to February 2018. IE, infective endocarditis. 
Table 1 Baseline patient characteristics

\begin{tabular}{|c|c|c|c|c|}
\hline \multirow{2}{*}{ Variables } & Non-elderly & Elderly & Very elderly & \multirow[b]{2}{*}{$P$ value } \\
\hline & $(n=7803)$ & $(n=7874)$ & $(n=4990)$ & \\
\hline Age, years & $51(40-59)$ & $72(68-76)$ & $84(82-88)$ & $<0.001^{*}$ \\
\hline Male gender & $5508(70.6 \%)$ & $4899(62.2 \%)$ & $2196(44.0 \%)$ & $<0.001^{*}$ \\
\hline $\mathrm{BMI}, \mathrm{kg} / \mathrm{m}^{2}$ & $21.5(19.1-24.3)$ & $21.6(19.3-24.0)$ & $20.6(18.3-23.1)$ & $<0.001^{*}$ \\
\hline$<18.5$ & $1419(18.2 \%)$ & $1354(17.2 \%)$ & $1171(23.5 \%)$ & \\
\hline $18.5-24.9$ & $4393(56.3 \%)$ & $4678(59.4 \%)$ & $2657(53.2 \%)$ & \\
\hline $25.0-29.9$ & $1197(15.3 \%)$ & $1059(13.4 \%)$ & $463(9.3 \%)$ & \\
\hline$\geq 30$ & $331(4.2 \%)$ & $213(2.7 \%)$ & $76(1.5 \%)$ & \\
\hline Smoking & $3841(49.2 \%)$ & $3289(41.8 \%)$ & $1495(30.0 \%)$ & $<0.001^{*}$ \\
\hline Barthel Index & $100(50-100)$ & $75(5-100)$ & $25(0-85)$ & $<0.001^{\star}$ \\
\hline <20 (total dependence) & $1249(16.0 \%)$ & $1900(24.1 \%)$ & 1967 (39.4\%) & $<0.001^{*}$ \\
\hline 20-35 (severe dependence) & $261(3.3 \%)$ & $373(4.7 \%)$ & $310(6.2 \%)$ & \\
\hline 40-55 (moderate dependence) & $376(4.8 \%)$ & $589(7.5 \%)$ & $473(9.5 \%)$ & \\
\hline 60-95 (mild dependence) & $890(11.4 \%)$ & $856(10.9 \%)$ & $522(10.5 \%)$ & \\
\hline 100 (independence) & $4028(51.6 \%)$ & $2768(35.2 \%)$ & $848(17.0 \%)$ & \\
\hline JCS & & & & $<0.001^{\star}$ \\
\hline 0 (alert) & $6738(86.4 \%)$ & $6341(80.5 \%)$ & $3358(67.3 \%)$ & \\
\hline 1-3 (drowsy) & $710(9.1 \%)$ & $1058(13.4 \%)$ & $1156(23.2 \%)$ & \\
\hline 10-30 (somnolence) & $196(2.5 \%)$ & $284(3.6 \%)$ & $318(6.4 \%)$ & \\
\hline 100-300 (coma) & $159(2.0 \%)$ & $191(2.4 \%)$ & $158(3.2 \%)$ & \\
\hline Hospital volume & & & & $<0.001^{*}$ \\
\hline Low $(<4)$ & $183(2.3 \%)$ & $256(3.3 \%)$ & $282(5.7 \%)$ & \\
\hline Middle $(4 \leq$ and $<14)$ & $1033(13.2 \%)$ & $1213(15.4 \%)$ & $1139(22.8 \%)$ & \\
\hline High $(\geq 14)$ & 6587 (84.4\%) & $6405(81.3 \%)$ & $3569(71.5 \%)$ & \\
\hline Clinical training hospital & $6820(87.4 \%)$ & $6641(84.3 \%)$ & $4043(81.0 \%)$ & $<0.001^{*}$ \\
\hline Emergent admission & $5874(75.3 \%)$ & $6163(78.3 \%)$ & $4266(85.5 \%)$ & $<0.001^{*}$ \\
\hline Pre-hospital home medical care & $60(0.8 \%)$ & $142(1.8 \%)$ & $288(5.8 \%)$ & $<0.001^{*}$ \\
\hline \multicolumn{5}{|l|}{ Comorbid conditions } \\
\hline Hypertension & $1697(21.7 \%)$ & $2341(29.7 \%)$ & $1588(31.8 \%)$ & $<0.001^{*}$ \\
\hline Diabetes mellitus & $1068(13.7 \%)$ & $1666(21.2 \%)$ & 791 (15.9\%) & $<0.001^{\star}$ \\
\hline Dyslipidaemia & $537(6.9 \%)$ & $768(9.8 \%)$ & $437(8.8 \%)$ & $<0.001^{*}$ \\
\hline Atrial fibrillation & $423(5.4 \%)$ & $1031(13.1 \%)$ & $698(14.0 \%)$ & $<0.001^{\star}$ \\
\hline Malignancy & $224(2.9 \%)$ & $616(7.8 \%)$ & $397(8.0 \%)$ & $<0.001^{*}$ \\
\hline Chronic pulmonary disease & $191(2.4 \%)$ & $258(3.3 \%)$ & $210(4.2 \%)$ & $<0.001^{*}$ \\
\hline Chronic liver disease & $361(4.6 \%)$ & $327(4.2 \%)$ & $152(3.0 \%)$ & $<0.001^{*}$ \\
\hline Chronic renal disease & $529(6.8 \%)$ & $954(12.1 \%)$ & $471(9.4 \%)$ & $<0.001^{\star}$ \\
\hline Previous valve replacement & $78(1.0 \%)$ & $172(2.2 \%)$ & $35(0.7 \%)$ & $<0.001^{*}$ \\
\hline \multicolumn{5}{|l|}{ In-hospital complications } \\
\hline Heart failure & $2314(29.7 \%)$ & $2718(34.5 \%)$ & $1984(39.8 \%)$ & $<0.001^{\star}$ \\
\hline NYHA II & $385(4.9 \%)$ & $420(5.3 \%)$ & $206(4.1 \%)$ & $0.001^{*}$ \\
\hline NYHA III & $274(3.5 \%)$ & $319(4.1 \%)$ & $176(3.5 \%)$ & \\
\hline NYHA IV & $242(3.1 \%)$ & $269(3.4 \%)$ & $202(4.0 \%)$ & \\
\hline Stroke & $1071(13.7 \%)$ & $1011(12.8 \%)$ & $542(10.9 \%)$ & $<0.001^{*}$ \\
\hline Ischaemic & $903(11.6 \%)$ & $855(10.9 \%)$ & $484(9.7 \%)$ & $0.004^{*}$ \\
\hline Haemorrhagic & $216(2.8 \%)$ & $195(2.5 \%)$ & $66(1.3 \%)$ & $<0.001^{*}$ \\
\hline Embolism & $391(5.0 \%)$ & $217(2.8 \%)$ & $96(1.9 \%)$ & $<0.001^{*}$ \\
\hline Coronary & $37(0.5 \%)$ & $36(0.5 \%)$ & $23(0.5 \%)$ & 0.987 \\
\hline
\end{tabular}


Table 1 Continued

\begin{tabular}{|c|c|c|c|c|}
\hline \multirow{2}{*}{ Variables } & Non-elderly & Elderly & Very elderly & \\
\hline & $(n=7803)$ & $(n=7874)$ & $(n=4990)$ & $P$ value \\
\hline Spleen & $126(1.6 \%)$ & $70(0.9 \%)$ & $17(0.3 \%)$ & $<0.001^{\star}$ \\
\hline Kidney & $133(1.7 \%)$ & $26(0.3 \%)$ & $4(0.1 \%)$ & $<0.001^{*}$ \\
\hline Lung & $68(0.9 \%)$ & $25(0.3 \%)$ & $16(0.3 \%)$ & $<0.001^{\star}$ \\
\hline Abdominal artery & $3(0.0 \%)$ & $9(0.1 \%)$ & $4(0.1 \%)$ & 0.232 \\
\hline Extremities & $85(1.1 \%)$ & $62(0.8 \%)$ & $35(0.7 \%)$ & $0.039^{\star}$ \\
\hline Shock & $149(1.9 \%)$ & $141(1.8 \%)$ & $73(1.5 \%)$ & 0.165 \\
\hline DIC & $266(3.4 \%)$ & 277 (3.5\%) & $176(3.5 \%)$ & 0.912 \\
\hline
\end{tabular}

Data are expressed as the median (IQR) or number (percentage).

${ }^{*} \mathrm{P}$ values are significant.

BMI, body mass index; DIC, disseminated intravascular coagulation; JCS, Japan Coma Scale; NYHA, New York Heart Association.

intensive care units, inotropic therapy and ventilation support. Continuous renal replacement therapy and intermittent renal replacement therapy were more frequently provided to elderly patients. Very elderly patients received all intensive treatments less frequently. The proportions of surgical treatment were $37.1 \%, 28.5 \%$ and $9.3 \%$ in non-elderly, elderly and very elderly patients, respectively $(\mathrm{p}<0.001)$.

\section{Clinical outcomes}

Table 3 shows clinical outcomes. In-hospital mortality was $6.6 \%, 14.2 \%$ and $22.8 \%$ in non-elderly, elderly

Table 2 Antibiotics, echocardiography and procedures

\begin{tabular}{|c|c|c|c|c|}
\hline \multirow[b]{2}{*}{ Variables } & \multirow{2}{*}{$\begin{array}{l}\text { Non-elderly } \\
(\mathrm{n}=7803)\end{array}$} & \multirow{2}{*}{$\begin{array}{l}\text { Elderly } \\
(n=7874)\end{array}$} & \multirow{2}{*}{$\begin{array}{l}\text { Very elderly } \\
(n=4990)\end{array}$} & \multirow[b]{2}{*}{$P$ value } \\
\hline & & & & \\
\hline \multicolumn{5}{|c|}{ Antibiotics for more than 2 weeks } \\
\hline Penicillin system & $3364(43.1 \%)$ & $3177(40.3 \%)$ & $1730(34.7 \%)$ & $<0.001^{*}$ \\
\hline Cephem system & $2489(31.9 \%)$ & $2202(28.0 \%)$ & $1356(27.2 \%)$ & $<0.001^{*}$ \\
\hline Carbapenem & $600(7.7 \%)$ & $687(8.7 \%)$ & $458(9.2 \%)$ & $0.007^{\star}$ \\
\hline Aminoglycoside & $2961(37.9 \%)$ & $2468(31.3 \%)$ & $1153(23.1 \%)$ & $<0.001^{*}$ \\
\hline Glycopeptide & $1237(15.9 \%)$ & $1452(18.4 \%)$ & $783(15.7 \%)$ & $<0.001^{*}$ \\
\hline Daptomycin & $275(3.5 \%)$ & $298(3.8 \%)$ & $130(2.6 \%)$ & $0.001^{*}$ \\
\hline Linezolid & $142(1.8 \%)$ & $119(1.5 \%)$ & $45(0.9 \%)$ & $<0.001^{*}$ \\
\hline Antifungal antibiotics & $131(1.7 \%)$ & $237(3.0 \%)$ & $102(2.0 \%)$ & $<0.001^{*}$ \\
\hline Others & $1785(22.9 \%)$ & $2119(26.9 \%)$ & $1585(31.8 \%)$ & $<0.001^{*}$ \\
\hline \multicolumn{5}{|l|}{ Echocardiography } \\
\hline TTE & $7263(93.1 \%)$ & $7251(92.1 \%)$ & $4556(91.3 \%)$ & $0.001^{*}$ \\
\hline TEE & $4007(51.4 \%)$ & $3700(47.0 \%)$ & $1494(29.9 \%)$ & $<0.001^{*}$ \\
\hline \multicolumn{5}{|c|}{ Intensive treatment within 2 days after admission } \\
\hline Admission to $\mathrm{HCU}$ & $266(3.4 \%)$ & $305(3.9 \%)$ & $178(3.6 \%)$ & 0.289 \\
\hline Admission to ICU & 1255 (16.1\%) & 1055 (13.4\%) & 347 (7.0\%) & $<0.001^{*}$ \\
\hline Inotropic therapy & 1236 (15.8\%) & $1205(15.3 \%)$ & $500(10.0 \%)$ & $<0.001^{*}$ \\
\hline Ventilation Support & $754(9.7 \%)$ & $674(8.6 \%)$ & $237(4.7 \%)$ & $<0.001^{*}$ \\
\hline CRRT & $135(1.7 \%)$ & $175(2.2 \%)$ & $49(1.0 \%)$ & $<0.001^{*}$ \\
\hline IRRT & 348 (4.5\%) & $498(6.3 \%)$ & $145(2.9 \%)$ & $<0.001^{*}$ \\
\hline PMX-DHP & $36(0.5 \%)$ & $29(0.4 \%)$ & $7(0.1 \%)$ & $0.01^{*}$ \\
\hline Surgical treatment & $2894(37.1 \%)$ & $2246(28.5 \%)$ & $465(9.3 \%)$ & $<0.001^{*}$ \\
\hline
\end{tabular}

Data are expressed as number (percentage).

${ }^{*} P$ values are significant.

CRRT, continuous renal replacement therapy; HCU, high care unit; ICU, intensive care unit; IRRT, intermittent renal replacement therapy; PMX-DHP, Polymyxin B-immobilised fibre column-direct hemoperfusion; TEE, transoesophageal echocardiography; TTE, transthoracic echocardiography. 
Table 3 Clinical outcomes

\begin{tabular}{|c|c|c|c|c|}
\hline & Non-elderly & Elderly & Very elderly & \\
\hline Variables & $(n=7803)$ & $(n=7874)$ & $(n=4990)$ & $P$ value \\
\hline In-hospital mortality & $514(6.6 \%)$ & $1118(14.2 \%)$ & $1138(22.8 \%)$ & $<0.001^{\star}$ \\
\hline Length of hospital stay, days & $37(21-54)$ & $38(19-59)$ & $36(19-57.3)$ & $0.014^{*}$ \\
\hline Transfer to nursing home or other hospital & $2276(29.2 \%)$ & $3390(43.1 \%)$ & $2724(54.6 \%)$ & $<0.001^{\star}$ \\
\hline Post-hospital home medical care & $71(0.9 \%)$ & $157(2.0 \%)$ & $252(5.1 \%)$ & $<0.001^{\star}$ \\
\hline
\end{tabular}

Data are expressed as the median (IQR) or number (percentage).

${ }^{*} P$ values are significant.

and very elderly patients, respectively $(\mathrm{p}<0.001)$. Very elderly patients were transferred to nursing homes or other hospitals and received post-hospital home medical care more frequently $(\mathrm{p}<0.001)$.

\section{Surgical treatment among patients with in-hospital complications}

The proportions of surgical treatment among patients with specific in-hospital complications were compared between each age category (figure 2). The proportions of surgical treatment were $47.6 \%, 36.6 \%$ and $10.3 \%$ among patients with concomitant heart failure; $47.9 \%, 32.1 \%$ and $11.3 \%$ among those with stroke; and $46.8 \%, 30.0 \%$ and $7.3 \%$ among those with embolism for non-elderly, elderly and very elderly patients, respectively (all $\mathrm{p}<0.001$ ).

\section{Association between surgical treatment and in-hospital mortality in an unmatched and a propensity score matched cohort}

We evaluated the association between surgical treatment and in-hospital mortality in each age category using an unmatched and a propensity score matched cohort.

Patient characteristics after propensity score matching in non-elderly, elderly and very elderly patients are shown in online supplemental table 2a-c. All the variables in each age category were well balanced between patients with and without surgical treatment. Propensity score matching created 1785 pairs in non-elderly, 1625 in elderly, and 414 in very elderly patients.

Table 4 shows the association between surgical treatment and in-hospital mortality in an unmatched and a propensity score matched cohort. Surgical treatment was associated with lower in-hospital mortality in all groups, not only in the unmatched cohort (non-elderly, OR 0.60 (95\% CI 0.49 to 0.73 ); elderly, OR 0.67 (95\% CI 0.57 to 0.78 ); very elderly, 0.61 (95\% CI 0.47 to 0.78$)$ ) but also in the propensity score matched cohort (non-elderly, OR 0.52 (95\% CI 0.39 to 0.69$)$; elderly, OR 0.68 (95\% CI 0.55 to 0.84 ); very elderly, 0.61 ( $95 \%$ CI 0.43 to 0.85$)$ ).

\section{Risk factors of in-hospital mortality among IE patients aged 80 years or older}

In multivariable logistic regression analysis, older age, lower Barthel Index, higher JCS, hypertension, dyslipidemia, chronic renal disease, heart failure, stroke, DIC, and surgical treatment were associated with higher in-hospital mortality among IE patients aged 80 years or older (online supplemental table 3).

\section{DISCUSSION}

This nationwide inpatient cohort study produced several important findings. First, the proportion of very

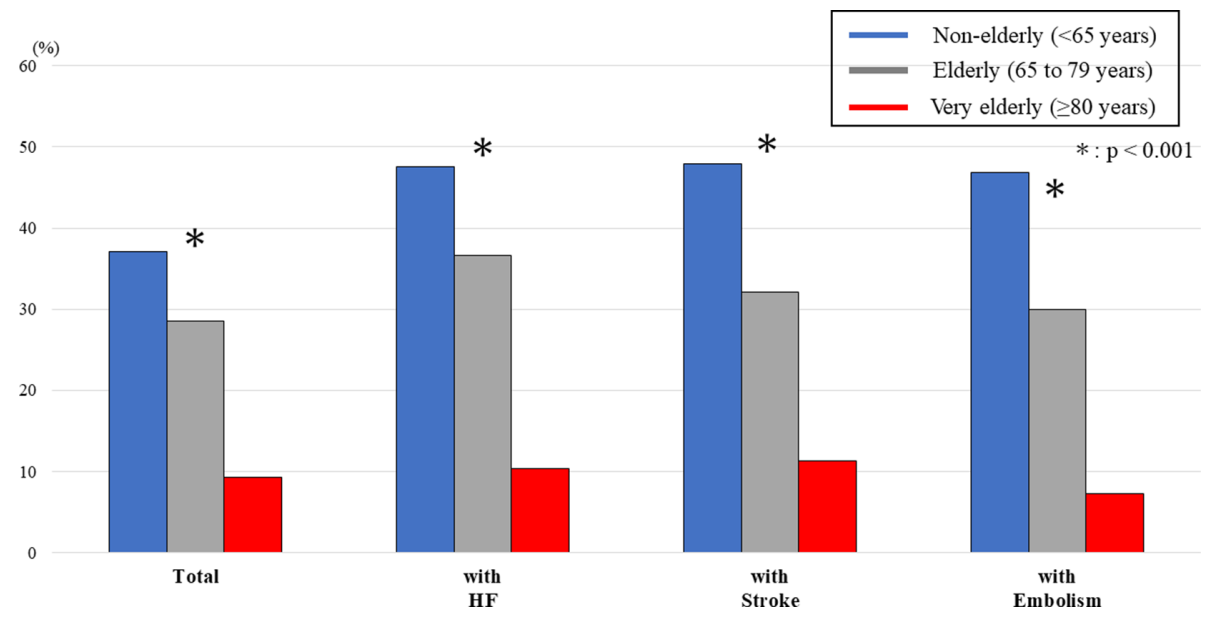

Figure 2 Proportions of surgical treatment for IE according to age category among patients with in-hospital complications. The figure shows that surgical treatment was performed less frequently with advancing age. The tendency was even more pronounced in the presence of complications such as heart failure, stroke and embolism. IE, infective endocarditis. 
Table 4 Association between surgical treatment and in-hospital mortality in an unmatched and a propensity score matched cohort

\begin{tabular}{|c|c|c|c|c|c|c|c|c|}
\hline \multirow[b]{3}{*}{ Subgroup } & \multicolumn{4}{|c|}{ Unmatched cohort } & \multicolumn{4}{|c|}{ Propensity score matched cohort } \\
\hline & \multicolumn{2}{|c|}{ In-hospital mortality } & \multirow[b]{2}{*}{$\begin{array}{l}\text { OR } \\
(95 \% \mathrm{Cl})\end{array}$} & \multirow[b]{2}{*}{ P value } & \multicolumn{2}{|c|}{ In-hospital mortality } & \multirow[b]{2}{*}{$\begin{array}{l}\text { OR } \\
(95 \% \mathrm{Cl})\end{array}$} & \multirow[b]{2}{*}{$P$ value } \\
\hline & $\begin{array}{l}\text { Surgical } \\
\text { treatment } \\
(-)\end{array}$ & $\begin{array}{l}\text { Surgical } \\
\text { treatment } \\
\text { (+) }\end{array}$ & & & $\begin{array}{l}\text { Surgical } \\
\text { treatment } \\
(-)\end{array}$ & $\begin{array}{l}\text { Surgical } \\
\text { treatment } \\
(+)\end{array}$ & & \\
\hline Non-elderly & $\begin{array}{l}377 / 4909 \\
(7.7 \%)\end{array}$ & $\begin{array}{l}137 / 2894 \\
(4.7 \%)\end{array}$ & $\begin{array}{l}0.60 \\
(0.49 \text { to } 0.73)\end{array}$ & $<0.001^{*}$ & $\begin{array}{l}151 / 1785 \\
(8.5 \%)\end{array}$ & $\begin{array}{l}82 / 1785 \\
(4.6 \%)\end{array}$ & $\begin{array}{l}0.52 \\
(0.39 \text { to } 0.69)\end{array}$ & $<0.001^{*}$ \\
\hline Elderly & $\begin{array}{l}873 / 5628 \\
(15.5 \%)\end{array}$ & $\begin{array}{l}245 / 2246 \\
(10.9 \%)\end{array}$ & $\begin{array}{l}0.67 \\
(0.57 \text { to } 0.78)\end{array}$ & $<0.001^{*}$ & $\begin{array}{l}242 / 1625 \\
(14.9 \%)\end{array}$ & $\begin{array}{l}173 / 1625 \\
(10.6 \%)\end{array}$ & $\begin{array}{l}0.68 \\
(0.55 \text { to } 0.84)\end{array}$ & $<0.001^{*}$ \\
\hline Very elderly & $\begin{array}{l}1065 / 4525 \\
(23.5 \%)\end{array}$ & $\begin{array}{l}73 / 465 \\
(15.7 \%)\end{array}$ & $\begin{array}{l}0.61 \\
\text { (0.47 to } 0.78)\end{array}$ & $<0.001^{*}$ & $\begin{array}{l}104 / 414 \\
(25.1 \%)\end{array}$ & $\begin{array}{l}70 / 414 \\
(16.9 \%)\end{array}$ & $\begin{array}{l}0.61 \\
(0.43 \text { to } 0.85)\end{array}$ & $0.004^{*}$ \\
\hline
\end{tabular}

${ }^{*} \mathrm{P}$ values are significant.

elderly patients among the whole IE population is obviously increasing whereas that of non-elderly patients is decreasing. Second, surgical treatment was performed on more than one-third of non-elderly patients, but on less than $10 \%$ of very elderly patients. Third, surgical treatment was beneficially associated with in-hospital mortality not only in non-elderly and elderly patients, but also in very elderly patients in both an unmatched and a propensity score matched cohort.

IE has become increasingly frequent in aged patients, especially in very elderly patients, over the past few decades. Shah et al reported that IE incidence in very elderly patients had doubled while remaining static or decreasing in the younger population over the past two decades, ${ }^{9}$ which indicates that IE in very elderly people is becoming an important issue in ageing societies. This escalation of IE among very elderly individuals is multifactorial, and includes changes in the incidence of degenerative valvular heart disease, an increase in invasive therapeutic cardiac interventions and improvements in survival rate for multiple comorbidities. ${ }^{12}$ Several studies have reported the similarities and the differences of IE among elderly compared with non-elderly patients, some of which showed the conflicting result regarding clinical characteristics such as causative microorganisms and echocardiographic findings. ${ }^{10-17}$ This contradiction may be explained by the diversity in health conditions across elderly people. Ageing is a highly variable process characterised by a wide spectrum of conditions: some aged individuals are healthy whereas others are bedridden. Contrasting study findings may also reflect inconsistent definitions of 'elderly', which can range from over 65 years to over 70 years. ${ }^{10-17}$

To the best of our knowledge, the present study is one of the largest to focus on IE among very elderly patients. The large sample enabled us to comprehensively investigate the characteristics of IE among very elderly patients in a clinical setting. Our overall cohort seemed relatively older than participants in other epidemiological studies. $^{25} 7-9$ This possibly reflects the fact that Japan is a representative ageing society, and is consistent with our previous study findings. ${ }^{25}$ Although men dominated this cohort, the proportion of women increased with age, similar to previous studies. ${ }^{12}{ }^{26}$ Regarding in-hospital complications, heart failure was more common in very elderly patients, whereas vascular manifestations of IE, such as stroke and other embolic events, were less common in very elderly patients. Patients with advanced age are prone to concomitant heart failure symptoms owing to underlying heart disease and degenerative changes; in addition, age-related decline in immune system and haemostatic function contributes to fewer embolic events with gradual progression of vegetation formation. ${ }^{10} 1227$ Very elderly patients received TEE and antibiotic treatment less frequently than patients in the other two age categories. Up to 6 weeks of antibiotic therapy to eradicate the growing bacteria present in the IE vegetation is an established medical treatment recommended in the American Heart Association and the European Society of Cardiology guidelines. ${ }^{18}{ }^{19}$ Moreover, TEE may be a more practical tool than transthoracic echocardiography for elderly patients with IE because valvular calcification, which is commonly seen in elderly patients, makes it difficult to evaluate the presence of the vegetation and the vegetation itself is smaller than that in non-elderly patients. ${ }^{17}$ The less usage of TEE in very elderly patients in this study can be attributed to several factors. The first reason is the less complexity of the valve lesion in very elderly patients with surgical treatment. The other reasons could be that the number of surgical treatments itself is less in very elderly patient, and that the very elderly have a higher hurdle for the invasive TEE procedures than non-elderly or elderly patients. Low frequency of TEE and antibiotic treatment may be associated with worse in-hospital mortality in very elderly patients, and further study is warranted to explore this association.

Surgical treatment is a cornerstone of IE treatment, especially in cases with decompensated heart failure and repeated emboli. However, in the real-world clinical setting, elderly patients tend to receive more conservative treatment, and a low proportion undergoes surgical treatment owing to concerns about surgical complications. ${ }^{12} 28$ 
The validity of surgical treatment among elderly patients has been investigated by several retrospective analyses focusing on patients over 65 or 70 years. ${ }^{10-17}$ Lin et al investigated the mid-term outcome of left-sided native valve IE in 179 patients and concluded that mid-term outcomes are promising once elderly patients over 65 years are stabilised by surgical treatment. ${ }^{14}$ However, there are scarce clinical data on the efficacy of surgical treatment for IE among the very elderly population. One randomised controlled trial of surgical treatment for IE excluded very elderly patients over 80 years old. ${ }^{29}$ Our nationwide study investigated the current status of surgical treatment in very elderly patients, and indicated that the proportion of surgical treatment for very elderly patients with IE was significantly lower than in younger patients $(<10 \%)$. This tendency was more pronounced among those with specific complications such as heart failure, stroke and embolic events, which could be an indication of surgical treatment. However, our analyses also showed an inverse association between surgical treatment and in-hospital mortality among very elderly patients in a propensity score matched cohort that included a wide variety of confounding factors. This result indicates that surgical treatment may be an appropriate therapeutic option for selected patients with IE, even in very elderly patients. Our findings are consistent with the description in the European Society of Cardiology guideline: 'Age per se is not a contraindication to surgery'. ${ }^{19}$ However, as the OR for very elderly patients was higher than that for non-elderly patients, the selection of optimal candidates for surgical treatment requires care.

The present study has several clinical implications. This comprehensive analysis of Japanese patients showed a rapidly increasing proportion of IE among very elderly patients, which is consistent with other epidemiological studies. ${ }^{59}$ Therefore, optimal management of IE in very elderly patients is becoming an important issue. Of note, implementation of surgical treatment for IE among very elderly patients was obviously low (less than $10 \%$ ) in our study. The propensity score analysis indicated an inverse association between surgical treatment and in-hospital mortality even in very elderly patients; therefore, appropriate patient selection for surgical treatment is required irrespective of age. The mechanism of IE in very elderly people is more complicated than in non-elderly people, so optimal decision making that includes early diagnosis and therapeutic strategies should be facilitated using a multidisciplinary approach. Further studies are needed to elucidate appropriate management for IE among very elderly patients.

We acknowledge several study limitations. First, although the reported validity of the diagnoses and procedures in our database was high, ${ }^{30}$ recorded diagnoses are generally considered less well validated because of the nature of administrative data and retrospective studies. Second, this database lacks some clinical data on causative micro-organisms, infected valves, the location and size of vegetation, and cardiac function. In particular, detailed past surgical histories and details of the surgeries performed on IE are lacking, however, the surgical results may be influenced by the complexity of valve lesions and surgical procedures. Third, we defined the antibiotic drugs used more than 2 weeks as drugs used for IE, but this might be insufficient to determine whether those antibiotic drugs were used for IE. Fourth, the database does not include any information after discharge, so long-term mortality could not be assessed. Finally, this was a retrospective observational study with non-random treatment assignment; therefore, the results may be biased by unmeasured confounders. However, several confounders (patient background, activities of daily living, comorbidities, in-hospital complications, in-hospital acute care) were adjusted using propensity score matching. Despite these limitations, and given the difficulty of implementing a randomised controlled trial of surgical treatment for IE in very elderly patients owing to ethical aspects, we believe this large-scale database study is useful in indicating the beneficial potential of surgical treatment for very elderly patients.

\section{CONCLUSION}

The analysis of a nationwide inpatient database showed that IE among very elderly patients is increasing and is associated with worse in-hospital mortality than in nonelderly patients. Although surgical treatment for IE was less frequently performed in very elderly patients, it was associated with lower in-hospital mortality in not only non-elderly and elderly patients but also in very elderly patients, suggesting the clinical importance of selecting optimal candidates for surgical treatment even in very elderly patients with IE.

Acknowledgements We thank Diane Williams, PhD, from Edanz Group (https://enauthor-services.edanz.com/ac) for editing a draft of this manuscript.

Contributors HKiriyama wrote the first draft of the manuscript. HKaneko, HI, KM, TJ and HY supported the statistical analysis. HKaneko, HI, TK, KM, TJ, KF, MD, NT, $\mathrm{HM}, \mathrm{HY}$ and IK edited and revised for important intellectual content. All the authors approved the submitted version of the manuscript.

Funding This work was supported by grants from the Ministry of Health, Labour and Welfare, Japan (19AA2007 and H30-Policy-Designated-004), and the Ministry of Education, Culture, Sports, Science and Technology, Japan (17H04141).

Competing interests Research funding and scholarship funds (HKaneko and KF) from Medtronic Japan, Abbott Medical Japan, Boston Scientific Japan and Fukuda Denshi, Central Tokyo.

Patient consent for publication Not required.

Ethics approval The present study was approved by the clinical research review board of the University of Tokyo (3501-(3)) on 25 December 2017. The requirement for informed consent was waived because of the anonymous nature of the database. We conducted this study in accordance with the Declaration of Helsinki.

Provenance and peer review Not commissioned; externally peer reviewed.

Data availability statement Data may be obtained from a third party and are not publicly available. Our data are from the Diagnosis Procedure Combination database, a nationwide Japanese inpatient database.

Open access This is an open access article distributed in accordance with the Creative Commons Attribution Non Commercial (CC BY-NC 4.0) license, which permits others to distribute, remix, adapt, build upon this work non-commercially, and license their derivative works on different terms, provided the original work is 
properly cited, appropriate credit is given, any changes made indicated, and the use is non-commercial. See: http://creativecommons.org/licenses/by-nc/4.0/.

\section{ORCID iDs}

Hiroyuki Kiriyama http://orcid.org/0000-0001-9663-3141

Hidehiro Kaneko http://orcid.org/0000-0003-2553-6170

\section{REFERENCES}

1 Pant S, Patel NJ, Deshmukh A, et al. Trends in infective endocarditis incidence, microbiology, and valve replacement in the United States from 2000 to 2011. J Am Coll Cardiol 2015;65:2070-6.

2 Olmos C, Vilacosta I, Fernández-Pérez C, et al. The Evolving Nature of Infective Endocarditis in Spain: A Population-Based Study (2003 to 2014). J Am Coll Cardiol 2017;70:2795-804.

3 Dayer MJ, Jones S, Prendergast B, et al. Incidence of infective endocarditis in England, 2000-13: a secular trend, interrupted timeseries analysis. Lancet 2015;385:1219-28.

4 Thornhill MH, Jones S, Prendergast B, et al. Quantifying infective endocarditis risk in patients with predisposing cardiac conditions. Eur Heart J 2018;39:586-95.

5 Toyoda N, Chikwe J, Itagaki S, et al. Trends in infective endocarditis in California and New York state, 1998-2013. JAMA 2017;317:1652-60.

6 Murdoch DR, Corey GR, Hoen B, et al. Clinical presentation, etiology, and outcome of infective endocarditis in the 21st century: the International Collaboration on Endocarditis-Prospective cohort study. Arch Intern Med 2009;169:463-73.

$7 \mathrm{Kim} \mathrm{JH}$, Lee HJ, Ku NS, et al. Infective endocarditis at a tertiary care hospital in South Korea. Heart 2021;107:135-41.

8 Lu KJ, Kearney LG, Ord M, et al. Age adjusted Charlson comorbidity index is an independent predictor of mortality over long-term follow-up in infective endocarditis. Int $J$ Cardiol 2013;168:5243-8.

9 Shah ASV, McAllister DA, Gallacher P, et al. Incidence, microbiology, and outcomes in patients hospitalized with infective endocarditis. Circulation 2020;141:2067-77.

10 Selton-Suty C, Hoen B, Grentzinger A, et al. Clinical and bacteriological characteristics of infective endocarditis in the elderly. Heart 1997;77:260-3.

11 Di Salvo G, Thuny F, Rosenberg V, et al. Endocarditis in the elderly: clinical, echocardiographic, and prognostic features. Eur Heart J 2003:24:1576-83.

12 Durante-Mangoni E, Bradley S, Selton-Suty C, et al. Current features of infective endocarditis in elderly patients: results of the International Collaboration on Endocarditis prospective cohort study. Arch Intern Med 2008;168:2095-103.

13 Wu Z, Chen Y, Xiao T, et al. The clinical features and prognosis of infective endocarditis in the elderly from 2007 to 2016 in a tertiary hospital in China. BMC Infect Dis 2019;19:937.

14 Lin C-Y, Lu C-H, Lee H-A, et al. Elderly versus non-elderly patients undergoing surgery for left-sided native valve infective endocarditis: a 10-year institutional experience. Sci Rep 2020;10:2690.
15 Gagliardi JP, Nettles RE, McCarty DE, et al. Native valve infective endocarditis in elderly and younger adult patients: comparison of clinical features and outcomes with use of the Duke criteria and the Duke Endocarditis Database. Clin Infect Dis 1998;26:1165-8.

16 Oliver L, Lavoute C, Giorgi R, et al. Infective endocarditis in octogenarians. Heart 2017;103:1602-9.

17 Werner GS, Schulz R, Fuchs JB, et al. Infective endocarditis in the elderly in the era of transesophageal echocardiography: clinical features and prognosis compared with younger patients. Am J Med 1996;100:90-7.

18 Baddour LM, Wilson WR, Bayer AS, et al. Infective endocarditis in adults: diagnosis, antimicrobial therapy, and management of complications: a scientific statement for healthcare professionals from the American Heart Association. Circulation 2015;132:1435-86.

19 Habib G, Lancellotti P, Antunes MJ. Esc guidelines for the management of infective endocarditis: the task force for the management of infective endocarditis of the European Society of cardiology (ESC). endorsed by: European Association for CardioThoracic Surgery (EACTS), the European Association of Nuclear Medicine (EANM). Eur Heart J 2015;2015:3075-128.

20 Kaneko $\mathrm{H}$, Itoh $\mathrm{H}$, Yotsumoto $\mathrm{H}$, et al. Association of cancer with outcomes in patients hospitalized for heart failure. Circ $J$ 2020;84:1771-8.

21 Itoh $\mathrm{H}$, Kaneko $\mathrm{H}$, Yotsumoto $\mathrm{H}$, et al. Serial changes in clinical presentations and outcomes of 5,740 patients requiring repeated hospital admissions (four or more times) due to worsened heart failure. Int Heart J 2020;61:1253-7.

22 Shigemori M, Abe T, Aruga T, et al. Guidelines for the management of severe head injury, 2nd edition guidelines from the guidelines Committee on the Management of Severe Head Injury, the Japan Society of Neurotraumatology. Neurol Med Chir 2012;52:1-30.

23 Mahoney FI, Barthel DW. Functional evaluation: the BARTHEL index. Md State Med J 1965;14:61-5.

24 Austin PC. Balance diagnostics for comparing the distribution of baseline covariates between treatment groups in propensity-score matched samples. Stat Med 2009;28:3083-107.

25 Kiriyama H, Daimon M, Nakanishi K, et al. Comparison between healthcare-associated and community-acquired infective endocarditis at tertiary care hospitals in Japan. Circ $J$ 2020;84:670-6

26 Nakatani S, Mitsutake K, Ohara T, et al. Recent picture of infective endocarditis in Japan--lessons from Cardiac Disease Registration (CADRE-IE). Circ J 2013;77:1558-64.

27 Cabell $\mathrm{CH}$, Pond KK, Peterson GE, et al. The risk of stroke and death in patients with aortic and mitral valve endocarditis. Am Heart $J$ 2001;142:75-80

28 López J, Revilla A, Vilacosta I, et al. Age-dependent profile of left-sided infective endocarditis: a 3-center experience. Circulation 2010;121:892-7.

29 Kang D-H, Kim Y-J, Kim S-H, et al. Early surgery versus conventional treatment for infective endocarditis. $N$ Engl J Med 2012;366:2466-73

30 Yamana $\mathrm{H}$, Matsui $\mathrm{H}$, Sasabuchi $\mathrm{Y}$, et al. Categorized diagnoses and procedure records in an administrative database improved mortality prediction. J Clin Epidemiol 2015;68:1028-35. 